\title{
FitosSOCIOLOGIA DO COMPONENTE ARBUSTIVO-ARBÓREO DE FLORESTAS Semidecíduas costeiras da Região de Emerenças, Área de Proteção Ambiental do Pau Brasit, Armação dos Búzios, Rio de Janeiro, Brasil
}

\author{
Bruno Coutinho Kurtz ${ }^{1,2}$, Cyl Farney Catarino de Sá ${ }^{1} \&$ Daniele Oliveira da Silva ${ }^{1}$
}

\begin{abstract}
ReSUMO
(Fitossociologia do componente arbustivo-arbóreo de florestas semidecíduas costeiras da região de Emerenças, Área de Proteção Ambiental do Pau Brasil, Armação dos Búzios, Rio de Janeiro, Brasil) O município de Armação dos Búzios, RJ, faz parte da região de Cabo Frio, considerada um dos 14 Centros de Diversidade Vegetal do Brasil. Para a caracterização da composição florística e estrutura do componente arbustivoarbóreo (DAP $\geq 5 \mathrm{~cm}$ ) de florestas sobre maciços litorâneos deste município, foram implantados cinco blocos de cinco parcelas de 10 × 20 m, distribuídos em diferentes encostas (total de 0,5 ha). Foram amostrados 1193 indivíduos, 98 espécies e 36 famílias. Myrtaceae e Fabaceae (20 e 11 espécies) destacaram-se em riqueza e Euphorbiaceae, em número de indivíduos (39\% do total). As espécies mais importantes foram Pachystroma longifolium $(\mathrm{VI}=31,9)$, Sebastiania nervosa $(30,6)$, Chrysophyllum lucentifolium $(11,3)$, Machaerium pedicellatum (10,5), Guapira opposita (9,9), Philyra brasiliensis (9,9), Capparis flexuosa $(9,1)$, Lonchocarpus virgilioides (8,2), Syagrus romanzoffiana (7,6) e Acosmium lentiscifolium (7,5). O índice de Shannon (H') foi de 3,60 nat.ind. ${ }^{-1}$ e a equabilidade (J') foi de 0,79 . A distribuição espacial das espécies parece estar condicionada às características ecológicas de cada encosta, como resultado de sua orientação. As florestas estudadas apresentaram, em geral, similaridade (Jaccard) muito baixa com outras florestas fluminenses.
\end{abstract}

Palavras-chave: fitossociologia; similaridade de Jaccard; Floresta Atlântica; região de Cabo Frio; Rio de Janeiro.

\section{Abstract}

(Phytosociology of the shrub-tree layer of semideciduous coastal forests in the Emerenças region, Pau Brasil Environmental Protection Area, Armação dos Búzios, Rio de Janeiro, Brazil) The municipality of Armação dos Búzios, Rio de Janeiro state, is included in the Cabo Frio region, one of the 14 Centres of Plant Diversity in Brazil. Aiming to characterize floristics and structure of the shrub-tree layer $(\mathrm{DBH} \geq 5 \mathrm{~cm})$ of forests on coastal hills in this municipality, five sets of five $10 \times 20 \mathrm{~m}$ plots were established on different slopes (total of $0.5 \mathrm{ha}$ ). The survey included 1193 individuals, 98 species and 36 families. Myrtaceae and Fabaceae (20 and 11 species) were the richest families, and Euphorbiaceae was the most abundant, comprising 39\% of the individuals. The most important species were Pachystroma longifolium (IV = 31.9), Sebastiania nervosa (30.6), Chrysophyllum lucentifolium (11.3), Machaerium pedicellatum (10.5), Guapira opposita (9.9), Philyra brasiliensis (9.9), Capparis flexuosa (9.1), Lonchocarpus virgilioides (8.2), Syagrus romanzoffiana (7.6) and Acosmium lentiscifolium (7.5). The Shannon index ( $\left.\mathrm{H}^{\prime}\right)$ was 3.60 nat.ind. ${ }^{-1}$ and the evenness index $\left(\mathrm{J}^{\prime}\right)$ was 0.79 . Species distribution seems to be influenced by the ecological characteristics of each slope, as a result of its orientation. The forests studied showed, in general, very low Jaccard's similarity with other forests from Rio de Janeiro. Key words: phytosociology; Jaccard's similarity; Atlantic forest complex; Cabo Frio region; Rio de Janeiro state.

\section{INTRODUÇÃO}

O município de Armação dos Búzios faz parte do Centro de Diversidade Vegetal da Região de Cabo Frio (Araujo 1997), uma das 14 regiões brasileiras assim consideradas pelo WWF e IUCN (Davis et al. 1997), que, num esforço mundial, estabeleceram Centros de Diversidade Vegetal em todos os continentes.
Situada no domínio da Floresta Atlântica, a região de Cabo Frio cobre uma área com cerca de $1.500 \mathrm{~km}^{2}$, onde se destacam três unidades fisiográficas: planícies arenosas costeiras e terras baixas; colinas baixas das penínsulas de Cabo Frio - Armação dos Búzios e ilhas costeiras; e colinas interioranas, com até cerca de $500 \mathrm{~m}$ de altitude. A região está

Artigo recebido em 05/2008. Aceito para publicação em 02/2009.

${ }^{1}$ Instituto de Pesquisas Jardim Botânico do Rio de Janeiro, R. Pacheco Leão 915, 22460-030, Rio de Janeiro, RJ, Brasil

${ }^{2}$ Autor para correspondência: e-mail: bkurtz@jbrj.gov.br 
submetida a um clima sui generis para o litoral sudeste brasileiro, onde a pluviosidade média anual atinge $800 \mathrm{~mm}$ próximo à cidade de Cabo Frio (Araujo 1997, 2000).

A cobertura vegetal varia de acordo com a situação fisiográfica e distância do mar, prevalecendo formações de restinga, de Floresta Atlântica e de um tipo arbustivoarbóreo que recobre os maciços litorâneos entre Arraial do Cabo e Armação dos Búzios, além de manguezais e brejos (Araujo et al. 1998). A vegetação arbustivo-arbórea que recobre estes maciços está aparentemente condicionada à história paleo-evolutiva e ao clima atual. Segundo Ab'Saber (1974), tratase de um remanescente de vegetação existente durante os períodos glaciais do pleistoceno, mais secos e frios, já tendo sido classificada como uma disjunção fisionômico-ecológica da estepe nordestina (Ururahy et al. 1987).

As áreas de vegetação mapeadas e interpretadas por Ururahy et al. (1983) como 'Região da Estepe', nas folhas SF.23/24 Rio de Janeiro/Vitória do Projeto RADAMBRASIL, com base nos relatos de Ule (1901 (1967)), nas postulações de Ab'Saber (1977) e em análises radargramétricas, foram estudadas por Sá (2006) quanto à estrutura e florística. A partir da comparação das listas de angiospermas do Centro de Diversidade de Cabo Frio e das caatingas, este último autor concluiu não haver similaridade florística entre estas áreas. Constatou também a baixa similaridade com outras florestas fluminenses.

Entretanto, sua similaridade fisionômica com as caatingas foi frequientemente utilizada para descaracterizar estas formações como pertencentes ao bioma Mata Atlântica, justificando sua supressão para a implantação de empreendimentos imobiliários (Sá 2006). Isto foi, na realidade, um grande erro que levou à destruição de trechos significativos de formações vegetais ainda pouco estudadas e de grande valor para a conservação, embora a conservação destes ambientes já fosse proposta por Ururahy et al. (1983). Informações sobre as formações florestais da área estão disponíveis em Araujo et al. (1998), Farág (1999), Sá (2006) e Dantas et al. (2009).

De acordo com Scarano (2002), no complexo da Floresta Atlântica fluminense, as florestas secas costeiras da região de Cabo Frio são denominadas 'habitats marginais', assim como os campos de altitude, as florestas inundadas e as restingas, em função das condições ambientais estressantes para as plantas.

Atualmente, a área localizada entre a praia de Tucuns e a ponta esquerda da praia do Peró, aqui denominada região de Emerenças, apresenta os maiores remanescentes florestais do município de Armação dos Búzios, situados sobre os maciços litorâneos e sobre a planície colúvio-aluvial. Esta região está incluída na Área de Proteção Ambiental do Pau Brasil (APA do Pau Brasil), em sua Zona de Preservação da Vida Silvestre (ZPVS), o que não garante, entretanto, a sua proteção efetiva, em função da fragilidade deste tipo de unidade de conservação e da exacerbada cobiça por quaisquer terras nesta área de elevada diversidade florística.

Os objetivos deste estudo foram: 1) caracterizar a composição florística e a estrutura fitossociológica do componente arbustivo-arbóreo de formações florestais sobre maciços litorâneos da região de Emerenças, APA do Pau Brasil, município de Armação dos Búzios; e 2) compará-las a outras florestas fluminenses.

\section{Material e Métodos}

\section{Área de estudo}

A Área de Proteção Ambiental do Pau Brasil (APA do Pau Brasil), criada pelo Decreto Estadual no 31.346, de 6 de junho de 2002, está situada nos municípios de Cabo Frio e Armação dos Búzios. Sob administração da Instituto Estadual do Ambiente - INEA, esta unidade tem entre seus objetivos 'preservar espécies raras, endêmicas e ameaçadas de extinção ou insuficientemente conhecidas da fauna e da flora nativas'. Na 
porção norte da APA, localiza-se a serra das Emerenças que, embora de baixa altitude (180 $\mathrm{msm}$ ), destaca-se na paisagem regional.

A cobertura vegetal apresenta, de um modo geral, porte baixo e aspecto xeromórfico, com a ocorrência de Pilosocereus ulei (K. Schum.) Byles \& G.D. Rowley, que imprime aspecto marcante à região, sobretudo nas áreas costeiras. Nos maciços litorâneos, apenas em locais mais abrigados e úmidos, objeto do presente estudo, a vegetação torna-se mais robusta, com fisionomia tipicamente florestal, embora de porte ainda reduzido. Já nas planícies colúvio-aluviais, a fisionomia é florestal, com predominância de espécies caducifólias, imprimindo aparência acinzentada à vegetação (Araujo et al. 1998; Farág 1999).
De acordo com Farág (1999) e Sá (2006), a formação florestal corresponde à floresta estacional semidecídua.

\section{Amostragem e análise dos dados}

A amostragem foi realizada entre a praia de Tucuns e a ponta esquerda da praia do Peró, na região de Emerenças. Foi utilizado o método de parcelas (Mueller-Dombois \& Ellenberg 1974; Martins 1993), tendo sido implantados cinco blocos de cinco parcelas contíguas de $10 \times 20 \mathrm{~m}$, entre $10-160 \mathrm{~m}$ de altitude, distribuídos em diferentes encostas: três blocos (A-C) na serra das Emerenças e dois (D-E) em pequeno maciço perto da praia de Caravelas (Fig. 1). Os blocos A e D foram implantados em encostas voltadas para o
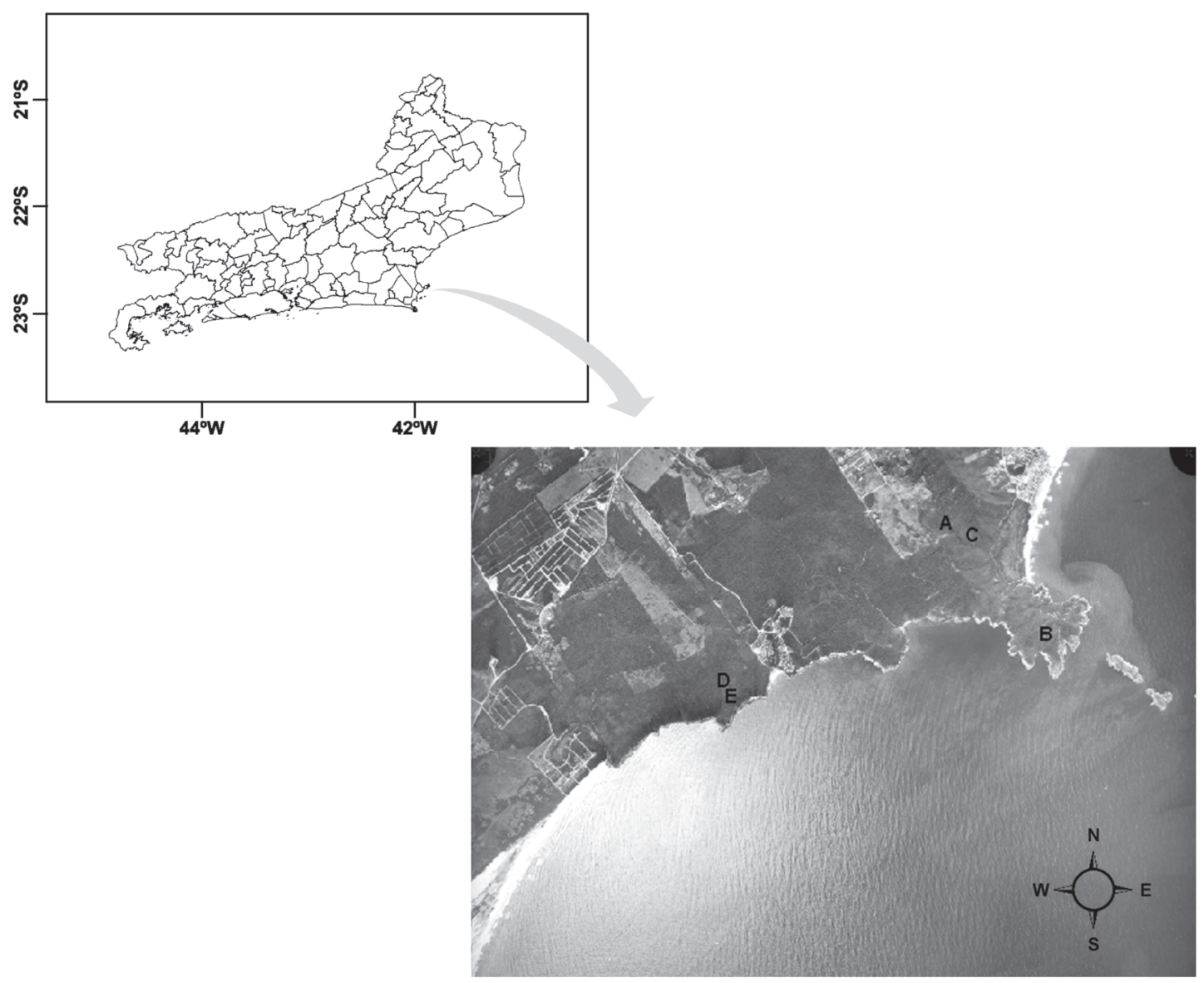

Figura 1 - Fotografia aérea mostrando a localização dos cinco blocos de parcelas (A-E) implantados em florestas da região de Emerenças, Área de Proteção Ambiental do Pau Brasil, Armação dos Búzios, RJ. 
quadrante Noroeste; os blocos B e E, em encostas voltadas para o quadrante Sul; e o bloco $\mathrm{C}$, em encosta voltada para o quadrante Leste. A amostragem totalizou 0,5 ha. As parcelas foram alocadas próximo às grotas ou em locais abrigados, onde a vegetação adquire fisionomia arbórea baixa, em áreas aparentemente em bom estado de conservação. Foram incluídos todos os indivíduos arbustivo-arbóreos vivos com diâmetro à altura do peito maior ou igual a $5 \mathrm{~cm}(\mathrm{DAP} \geq 5 \mathrm{~cm})$. Os trabalhos de campo foram realizados em períodos alternados, entre junho de 1998 e dezembro de 2000, totalizando mais de 40 dias.

O material botânico foi identificado por comparação com a coleção do herbário do Instituto de Pesquisas Jardim Botânico do Rio de Janeiro (RB), com o auxílio da literatura disponível e, sempre que possível, por especialistas. Os nomes das espécies foram baseados nas seguintes bases de dados: Tropicos e The International Plant Names Index. A classificação das plantas seguiu APG II (2003), sendo que a inclusão dos gêneros nas famílias baseou-se em Souza \& Lorenzi (2005). Os nomes populares para algumas espécies das áreas A-C foram obtidos de um informante local que auxiliou os trabalhos de campo. O material testemunho encontra-se depositado no herbário RB.

Os parâmetros fitossociológicos considerados foram: densidade relativa (DR), frequiência relativa (FR), dominância relativa (DoR) e valor de importância (VI) (Martins 1993). O índice de diversidade de Shannon (H') e a equabilidade (J'), para os quais foi utilizado logaritmo natural, seguiram Zar (1996). Para a avaliação da similaridade florística entre as encostas estudadas, utilizou-se a distância de Bray-Curtis. O método de agrupamento adotado na construção do dendrograma foi o da variância mínima (ou método de Ward; Valentin 2000). Os cálculos foram realizados pelo conjunto de programas FITOPAC 1.6 (Shepherd 2006).

Para a comparação da composição florística das florestas de Emerenças com outras florestas fluminenses, foi utilizado o coeficiente de similaridade de Jaccard (Valentin 2000), excluindo-se da análise as espécies não identificadas a este nível e espécies exóticas. Para tal, foram incluídos apenas trabalhos desenvolvidos em florestas ombrófilas e estacionais situadas em altitudes inferiores a $400 \mathrm{~m}$. De acordo com Mueller-Dombois \& Ellenberg (1974), valores de Jaccard > 0,25 $(25 \%)$ indicam similaridade florística entre as unidades comparadas.

\section{Resultados e Discussão}

Foram amostrados 1193 indivíduos, pertencentes a 98 espécies e 36 famílias (Tab. 1). Oitenta e um táxons foram identificados ao nível de espécie; 12 ao nível de gênero; e cinco ao nível de família. O número relativamente alto de espécies não totalmente identificadas se deu em função do grande volume de material estéril e, principalmente, do ainda escasso conhecimento florístico das florestas estacionais da região.

As famílias mais ricas foram Myrtaceae (20 espécies) e Fabaceae (11), seguidas de Euphorbiaceae (6), Rubiaceae (5) e Sapotaceae (5). Estas cinco famílias somaram quase metade (48\%) das espécies amostradas (Fig. 2). O gênero Eugenia L. destacou-se com 17 espécies. Dezessete famílias apresentaram apenas uma espécie. As famílias acima citadas estão entre as mais ricas em espécies arbóreas de florestas atlânticas semidecíduas de baixa altitude $(<700 \mathrm{~m})$ do sudeste brasileiro (Oliveira-Filho \& Fontes 2000); as quatro primeiras também se destacaram nas florestas estacionais da região de Cabo Frio estudadas por Sá (2006; DAP $\geq 2,5 \mathrm{~cm}$ ), sendo que Myrtaceae apresentou maior riqueza nas áreas mais elevadas.

Por outro lado, Lauraceae e Melastomataceae, com elevada riqueza nas formações florestais atlânticas, não foram amostradas no presente estudo, fato já observado na listagem preliminar das espécies do Centro de Diversidade de Cabo Frio (Araujo et al. 1998). Estes dados também estão 
Tabela 1 - Espécies arbustivo-arbóreas amostradas em florestas da região de Emerenças, Área de Proteção Ambiental do Pau Brasil, Armação dos Búzios, RJ, com seus nomes populares locais e indicação de material testemunho no RB. As siglas a seguir referem-se aos coletores: $\mathrm{CF}=\mathrm{Cyl}$ Farney C. de Sá; DO = Daniele Oliveira da Silva; BK = Bruno Coutinho Kurtz; AL = Adriana Q. Lobão; e $\mathrm{S} / \mathrm{R}$ = sem representação.

\begin{tabular}{|c|c|c|}
\hline Família/Espécie & Nome popular & Material testemunho \\
\hline \multicolumn{3}{|l|}{ ACHATOCARPACEAE } \\
\hline Achatocarpus praecox Griseb. & & CF $5263,5264,5265$ \\
\hline \multicolumn{3}{|l|}{ ANACARDIACEAE } \\
\hline Astronium graveolens Jacq. & & CF5268 \\
\hline Spondias cf. venulosa (Engl.) Engl. & & CF 5266, 5267 \\
\hline \multicolumn{3}{|l|}{ ANNONACEAE } \\
\hline Oxandra nitida R.E. Fr. & imbiú & CF 5269 \\
\hline Porcelia macrocarpa (Warm.) R.E. Fr. & & CF 5270 \\
\hline \multicolumn{3}{|l|}{ APOCYNACEAE } \\
\hline Aspidosperma gomezianum A. DC. & & DO54 \\
\hline Aspidosperma ramiflorum Müll. Arg. & pequeiá, pequiá & CF 5271,5272,5273 \\
\hline \multicolumn{3}{|l|}{ ARALIACEAE } \\
\hline Araliaceae indet. & bolera & CF 5276 \\
\hline \multicolumn{3}{|l|}{ ARECACEAE } \\
\hline Syagrus romanzoffiana (Cham.) Glassman & coqueiro & CF 5274 \\
\hline \multicolumn{3}{|l|}{ ASTERACEAE } \\
\hline Gochnatia polymorpha (Less.) Cabrera & aroeira do sertão & CF5275 \\
\hline \multicolumn{3}{|l|}{ BIGNONIACEAE } \\
\hline Tabebuia roseoalba (Ridl.) Sandwith & & DO 58 \\
\hline \multicolumn{3}{|l|}{ BRASSICACEAE } \\
\hline Capparis brasiliana DC. & & CF 5276 \\
\hline Capparis flexuosa (L.) L. & timbó & DO 85 \\
\hline \multicolumn{3}{|l|}{ CACTACEAE } \\
\hline Brasilopuntia brasiliensis (Willd.) A. Berger & jurubeba & $\mathrm{S} / \mathrm{R}$ \\
\hline \multicolumn{3}{|l|}{ CANNABACEAE } \\
\hline Celtis chichape (Wedd.) Miq. & limoeiro & CF5354 \\
\hline Celtis iguanaea (Jacq.) Sarg. & & CF5355 \\
\hline \multicolumn{3}{|l|}{ CLUSIACEAE } \\
\hline Clusia fluminensis Planch. \& Triana & & CF5277 \\
\hline Garcinia brasiliensis Mart. & & CF5278 \\
\hline \multicolumn{3}{|l|}{ ERYTHROXYLACEAE } \\
\hline Erythroxylum pulchrum A. St.-Hil. & & CF 5281 \\
\hline
\end{tabular}




\begin{tabular}{|c|c|c|}
\hline Família/Espécie & Nome popular & Material testemunho \\
\hline \multicolumn{3}{|l|}{ EUPHORBIACEAE } \\
\hline Actinostemon klotzschii (Didr.) Pax & estralador & CF 5285, 5286 \\
\hline Pachystroma longifolium (Nees) I.M. Johnst. & santa luzia & CF 5283 \\
\hline Philyra brasiliensis Klotzsch & espinho agulha & CF 5284 \\
\hline Sebastiania brasiliensis Spreng. & & $\mathrm{BK} s / \mathrm{n}^{\circ}$ \\
\hline Sebastiania nervosa (Müll. Arg.) Müll. Arg. & canela de veado & $\mathrm{DO} s / \mathrm{n}^{\circ}$ \\
\hline Euphorbiaceae indet. & & CF 5287 \\
\hline \multicolumn{3}{|l|}{ FABACEAE } \\
\hline Acosmium lentiscifolium Schott & seruera, saruera & CF5298 \\
\hline Caesalpinia pluviosa DC. & & CF5297 \\
\hline Chamaecrista ensiformis (Vell.) H.S. Irwin \& Barneby & jacarandá formiga & CF5296 \\
\hline Dalbergia frutescens (Vell.) Britton & & CF 5295 \\
\hline Lonchocarpus virgilioides Benth. & pau cachorro & CF5294 \\
\hline Machaerium leucopterum Vogel & jacarandá rosa & CF 5293 \\
\hline Machaerium pedicellatum Vogel & jacarandá rosa & CF 5292 \\
\hline Parapiptadenia pterosperma (Benth.) Brenan & cabiú pitanga & CF 5291 \\
\hline Peltogyne discolor Vogel & & CF 5290 \\
\hline Platymiscium floribundum Vogel & caixa d'água & CF5289 \\
\hline Zollernia glabra (Spreng.) Yakovlev & jacarandá formiga & CF 5288 \\
\hline \multicolumn{3}{|l|}{ MALPIGHIACEAE } \\
\hline Heteropterys schenckiana Nied. & & CF 5299, DO 55 \\
\hline \multicolumn{3}{|l|}{ MALVACEAE } \\
\hline Ceiba erianthos (Cav.) K. Schum. & & $\mathrm{BK} s / \mathrm{n}^{\circ}$ \\
\hline Guazuma crinita Mart. & vassoura & CF5351 \\
\hline Pseudobombax grandiflorum (Cav.) A. Robyns & paina & CF5280 \\
\hline Quararibea turbinata (Sw.) Poir. & & CF5279 \\
\hline \multicolumn{3}{|l|}{ MELIACEAE } \\
\hline Trichilia pseudostipularis (A. Juss.) C. DC. & & CF 5300, 5301 \\
\hline Trichilia sp. & limoeiro & CF5302 \\
\hline \multicolumn{3}{|l|}{ MORACEAE } \\
\hline Ficus hirsuta Schott & & CF5303 \\
\hline \multicolumn{3}{|l|}{ MYRTACEAE } \\
\hline Eugenia brasiliensis Lam. & & CF5312 \\
\hline Eugenia copacabanensis Kiaersk. & goiabeira vermelha & CF 5311 \\
\hline Eugenia excelsa O. Berg & goiabeira vermelha & CF 5310 \\
\hline Eugenia microcarpa O. Berg & goiabeira branca & CF5314 \\
\hline Eugenia neosilvestris Sobral & & CF 5313 \\
\hline Eugenia olivacea $\mathrm{O}$. Berg & & CF5315 \\
\hline Eugenia oxyoentophylla Kiaersk. & goiabeira vermelha & CF 5316, DO 87 \\
\hline Eugenia punicifolia (Kunth) DC. & goiabeira & CF 5308 \\
\hline Eugenia repanda $\mathrm{O} . \mathrm{Berg}$ & goiabeira & CF5309 \\
\hline Eugenia cf. rostrata O. Berg & goiabeira & CF 5317 \\
\hline Eugenia rotundifolia Casar. & goiabeira preta & CF 5304 \\
\hline Eugenia schottiana O. Berg & goiabeira & CF5305 \\
\hline
\end{tabular}




\begin{tabular}{|c|c|c|}
\hline Família/Espécie & Nome popular & Material testemunho \\
\hline Eugenia stictosepala Kiaersk. & & CF5306, DO 94 \\
\hline Eugenia aff. xanthoxyloides Cambess. & gabiroba & CF5307 \\
\hline Eugenia sp.1 & & CF 5321,5322 \\
\hline Eugenia sp.2 & goiabeira vermelha & CF 5323 \\
\hline Eugenia sp.3 & goiabeira & CF 5324, DO 89 \\
\hline Myrciaria cf. floribunda (H. West ex Willd.) O. Berg & & CF5318 \\
\hline Myrtaceae indet.1 & goiabeira & CF5319 \\
\hline Myrtaceae indet.2 & goiabeira preta & CF5320 \\
\hline \multicolumn{3}{|l|}{ NYCTAGINACEAE } \\
\hline Andradea floribunda Allemão & & CF5325 \\
\hline Guapira aff. areolata (Heimerl) Lundell & maria mole & CF5326 \\
\hline Guapira opposita (Vell.) Reitz & maria mole & CF 5327, 5328 \\
\hline \multicolumn{3}{|l|}{ OLACACEAE } \\
\hline Schoepfia brasiliensis A. DC. & & CF5329 \\
\hline \multicolumn{3}{|l|}{ OPILIACEAE } \\
\hline Agonandra excelsa Griseb. & & CF5330 \\
\hline \multicolumn{3}{|l|}{ PHYLLANTHACEAE } \\
\hline Discocarpus aff. pedicellatus Fiaschi \& Cordeiro & macanaíba preta & CF 5282, AL 308 \\
\hline Phyllanthus sp.1 & macanaíba branca & DO 108 \\
\hline Phyllanthus sp.2 & & $\mathrm{DO} 105, \mathrm{BK} \mathrm{s} / \mathrm{n}^{\circ}$ \\
\hline \multicolumn{3}{|l|}{ PHYTOLACCACEAE } \\
\hline Gallesia integrifolia (Spreng.) Harms & & CF5334 \\
\hline \multicolumn{3}{|l|}{ POLYGONACEAE } \\
\hline Coccoloba confusa R.A. Howard & & CF5331 \\
\hline Ruprechtia lundii Meisn. & caixa d'água & CF5332 \\
\hline \multicolumn{3}{|l|}{ RHAMNACEAE } \\
\hline Ziziphus glaziovii Warm. & & CF 5333, DO 15 \\
\hline \multicolumn{3}{|l|}{ RUBIACEAE } \\
\hline Alseis involuta K. Schum. & & CF5335 \\
\hline Coussarea capitata (Benth.) Benth. \& Hook. f. & & CF5336 \\
\hline Randia armata (Sw.) DC. & limão & CF5337 \\
\hline Rudgea ovalis Müll. Arg. & & CF 5338, DO 12 \\
\hline Simira sampaioana (Standl.) Steyerm. & goiabeira branca & CF5339 \\
\hline \multicolumn{3}{|l|}{ RUTACEAE } \\
\hline Almeidea rubra A. St.-Hil. & estralador preto & CF5340 \\
\hline Pilocarpus spicatus A. St.-Hil. & & DO53 \\
\hline Zanthoxylum tingoassuiba A. St.-Hil. & tinguá suiba & CF 5341, DO 100, 112 \\
\hline Rutaceae indet. & & CF5342 \\
\hline \multicolumn{3}{|l|}{ SAPINDACEAE } \\
\hline Allophylus puberulus Radlk. & & DO91 \\
\hline
\end{tabular}




\begin{tabular}{|c|c|c|}
\hline Família/Espécie & Nome popular & Material testemunho \\
\hline Talisia oliviformis (Kunth) Radlk. & & CF5343 \\
\hline \multicolumn{3}{|l|}{ SAPOTACEAE } \\
\hline Chrysophyllum gonocarpum (Mart. \& Eichler ex Miq.) Engl. & pequeiá & CF5344 \\
\hline Chrysophyllum janиariense Eichler & massaranduba & CF5346 \\
\hline Chrysophyllum lucentifolium Cronquist & jacuã, jacuá, jaquara & CF5345 \\
\hline Pouteria psammophila (Mart.) Radlk. & & CF5347 \\
\hline Pouteria reticulata (Engl.) Eyma & & CF5348 \\
\hline \multicolumn{3}{|l|}{ SIMAROUBACEAE } \\
\hline Simaba floribunda A. St.-Hil. & & CF5349 \\
\hline \multicolumn{3}{|l|}{ SOLANACEAE } \\
\hline Dyssochroma viridiflora Miers & & CF5350 \\
\hline \multicolumn{3}{|l|}{ ULMACEAE } \\
\hline Ampelocera glabra Kuhlm. & café & CF5351 \\
\hline Phyllostylon brasiliense Capan. ex Benth. \& Hook. f. & & CF5352 \\
\hline \multicolumn{3}{|l|}{ URTICACEAE } \\
\hline Urera baccifera (L.) Gaudich. ex Wedd. & urtiga & CF5353 \\
\hline \multicolumn{3}{|l|}{ VIOLACEAE } \\
\hline Rinorea laevigata (Sol. ex Ging.) Hekking & & $\mathrm{DO} 29$ \\
\hline
\end{tabular}

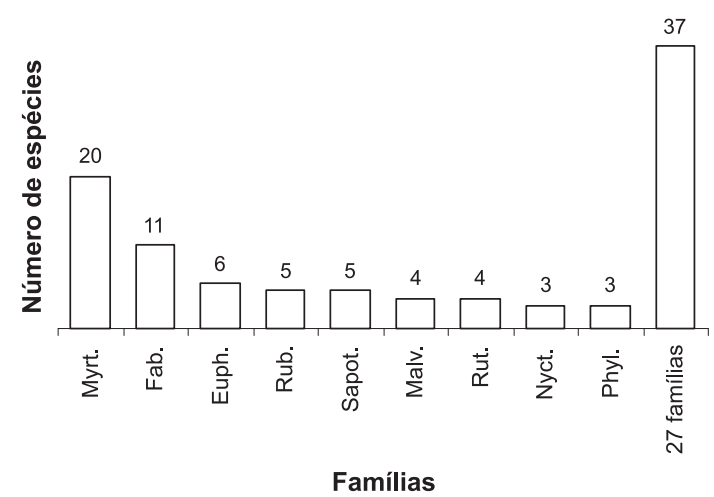

Figura 2 - Número de espécies arbustivo-arbóreas por família de florestas da região de Emerenças, Área de Proteção Ambiental do Pau Brasil, Armação dos Búzios, RJ. Myrt.: Myrtaceae; Fab.: Fabaceae; Euph.: Euphorbiaceae; Rub.: Rubiaceae; Sapot.: Sapotaceae; Malv.: Malvaceae; Rut.: Rutaceae; Nyct.: Nyctaginaceae; e Phyl.: Phyllanthaceae. de acordo com Gentry (1995), que menciona estas duas famílias como escassamente representadas em áreas secas dos neotrópicos, e com o estudo de Sá (2006), que, em quatro áreas de floresta estacional no referido Centro de Diversidade, só encontrou espécies destas famílias em duas: florestas no interior da península de Armação dos Búzios (Lauraceae: 2 spp.) e na ilha de Cabo Frio, onde as condições ambientais são mais mésicas que nas demais áreas (Lauraceae: 10 spp.; Melastomataceae: 2 spp.).

Em relação ao número de indivíduos, Euphorbiaceae apresentou grande destaque, com $39 \%$ do total amostrado (Fig. 3). De acordo com Richards (1981), a dominância por família, que consiste na preponderância numérica de espécies de uma mesma família, parece ser uma característica comum de 
florestas tropicais. Embora não se possa falar numa nítida dominância de Euphorbiaceae nas florestas estudadas, esta família se destacou mesmo em relação à Fabaceae e Myrtaceae, que somaram, respectivamente, 13,2 e 10,2\% dos indivíduos amostrados. Euphorbiaceae também apresentou elevada percentagem de indivíduos (DAP $\geq 2,5 \mathrm{~cm}$ ) em outras áreas de floresta estacional da região de Cabo Frio, variando de 12,6 a $23 \%$ e sendo a família mais ou uma das mais abundantes (Sá 2006).

A Tabela 2 lista as espécies e seus parâmetros fitossociológicos. Destacaram-se em importância Pachystroma longifolium (VI $=31,9)$ e Sebastiania nervosa $(30,6)$, a primeira principalmente pela dominância e a segunda pela densidade. Seguem-se Chrysophyllum lucentifolium (11,3), Machaerium pedicellatum (10,5), Guapira opposita (9,9), Philyra brasiliensis $(9,9)$, Capparis flexuosa $(9,1)$, Lonchocarpus virgilioides $(8,2)$, Syagrus romanzoffiana $(7,6)$ e Acosmium lentiscifolium $(7,5)$, que, com as primeiras, somaram $45,5 \%$ do VI. Vinte e quatro espécies $(24,5 \%$ do total) foram amostradas com apenas um indivíduo.

É interessante observar que, das 10 espécies de maior importância no presente estudo, apenas $S$. nervosa e $L$. virgilioides apresentaram destaque na estrutura de floresta sobre baixada, situada a menos de $3 \mathrm{~km}$, na própria APA do Pau Brasil (Farág 1999); as demais apresentaram pequena importância ou mesmo não foram amostradas $(C$. lucentifolium, M. pedicellatum, G. opposita e $S$. romanzoffiana). Comparando estas espécies com as 10 mais importantes nas áreas estudadas por Sá (2006), A. lentiscifolium, L. virgilioides, G. opposita e P. longifolium destacaram-se no interior da península de Armação dos Búzios; G. opposita, S. nervosa e A. lentiscifolium, em Cabo Frio; e apenas G. opposita, na serra de Sapiatiba. Não houve espécies em comum entre as 10 mais importantes do presente estudo e da ilha de

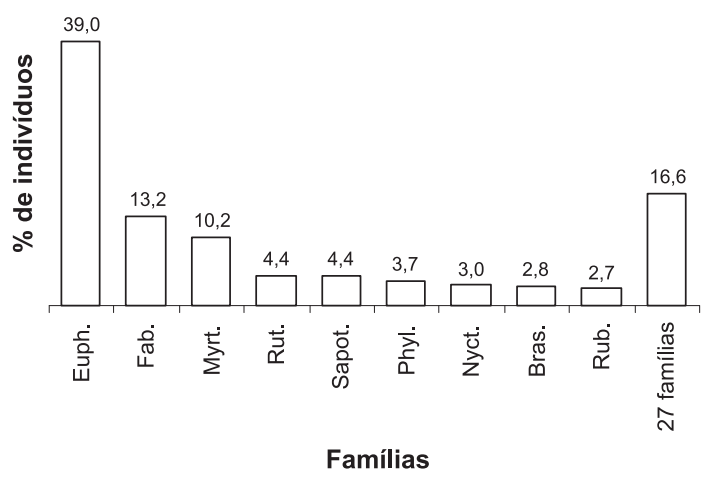

Figura 3 - Percentual de indivíduos arbustivo-arbóreos por família de florestas da região de Emerenças, Área de Proteção Ambiental do Pau Brasil, Armação dos Búzios, RJ. Euph.: Euphorbiaceae; Fab.: Fabaceae; Myrt.: Myrtaceae; Rut.: Rutaceae; Sapot.: Sapotaceae; Phyl.: Phyllanthaceae; Nyct.: Nyctaginaceae; Bras.: Brassicaceae; e Rub.: Rubiaceae.

Cabo Frio. G. opposita também se destacou na estrutura de florestas de restinga da região (Fernandes 2005; Sá \& Araujo 2009), indicando sua importância e relativa constância na estrutura das florestas do Centro de Diversidade de Cabo Frio. De acordo com Oliveira-Filho \& Fontes (2000), G. opposita é espécie generalista ('supertramp species') na Floresta Atlântica.

Por outro lado, não foi observado no presente estudo nenhum indivíduo de Caesalpinia echinata Lam. (pau-brasil), cujas populações estiveram bem representadas na floresta de baixada de Emerenças (Farág 1999) e escassamente na serra de Sapiatiba e em Cabo Frio (Sá 2006); muito embora nestas duas últimas áreas existam sítios com concentração de indivíduos de pau-brasil. De acordo com Capossoli \& Pereira (comunicação pessoal), estes indivíduos mostraram padrão de distribuição espacial agregado, o que pode justificar a raridade, ou mesmo ausência, da espécie nas áreas estudadas. Todos estes resultados ilustram como florestas muito próximas e submetidas a um mesmo clima geral podem apresentar composições e estruturas diversas. 
Tabela 2 - Espécies arbustivo-arbóreas amostradas em florestas da região de Emerenças, Área de Proteção Ambiental do Pau Brasil, Armação dos Búzios, RJ, em ordem decrescente de valor de importância, e seus respectivos parâmetros fitossociológicos. N: número de indivíduos; DR: densidade relativa (\%); DoR: dominância relativa (\%); FR: frequiência relativa (\%); e VI: valor de importância.

\begin{tabular}{|c|c|c|c|c|c|}
\hline Espécie & $\mathbf{N}$ & DR & DoR & FR & VI \\
\hline Pachystroma longifolium & 139 & 11,65 & 17,16 & 3,08 & 31,89 \\
\hline Sebastiania nervosa & 231 & 19,36 & 7,97 & 3,30 & 30,64 \\
\hline Chrysophyllum lucentifolium & 40 & 3,35 & 4,19 & 3,74 & 11,28 \\
\hline Machaerium pedicellatum & 39 & 3,27 & 3,50 & 3,74 & 10,51 \\
\hline Guapira opposita & 31 & 2,60 & 4,42 & 2,86 & 9,88 \\
\hline Philyra brasiliensis & 50 & 4,19 & 1,91 & 3,74 & 9,85 \\
\hline Capparis flexuosa & 30 & 2,51 & 2,63 & 3,96 & 9,11 \\
\hline Lonchocarpus virgilioides & 24 & 2,01 & 3,07 & 3,08 & 8,17 \\
\hline Syagrus romanzoffiana & 26 & 2,18 & 3,25 & 2,20 & 7,63 \\
\hline Acosmium lentiscifolium & 30 & 2,51 & 2,77 & 2,20 & 7,49 \\
\hline Oxandra nitida & 14 & 1,17 & 3,24 & 1,98 & 6,40 \\
\hline Machaerium leucopterum & 16 & 1,34 & 2,25 & 1,98 & 5,58 \\
\hline Alseis involuta & 13 & 1,09 & 2,07 & 2,20 & 5,37 \\
\hline Almeidea rubra & 29 & 2,43 & 1,13 & 1,76 & 5,32 \\
\hline Eugenia sp.3 & 17 & 1,42 & 1,17 & 2,64 & 5,24 \\
\hline Caesalpinia pluviosa & 7 & 0,59 & 3,17 & 1,10 & 4,85 \\
\hline Phyllanthus sp.1 & 21 & 1,76 & 0,56 & 2,42 & 4,74 \\
\hline Actinostemon klotzschii & 21 & 1,76 & 0,43 & 2,42 & 4,62 \\
\hline Discocarpus aff. pedicellatus & 16 & 1,34 & 1,93 & 0,88 & 4,15 \\
\hline Pseudobombax grandiflorum & 15 & 1,26 & 0,77 & 1,98 & 4,01 \\
\hline Eugenia sp.2 & 21 & 1,76 & 1,50 & 0,66 & 3,92 \\
\hline Eugenia rotundifolia & 19 & 1,59 & 0,49 & 1,76 & 3,84 \\
\hline Brasilopuntia brasiliensis & 11 & 0,92 & 0,84 & 1,98 & 3,75 \\
\hline Ampelocera glabra & 8 & 0,67 & 1,72 & 1,32 & 3,71 \\
\hline Astronium graveolens & 16 & 1,34 & 0,77 & 1,54 & 3,65 \\
\hline Ruprechtia lundii & 12 & 1,01 & 0,50 & 1,98 & 3,49 \\
\hline Pilocarpus spicatus & 19 & 1,59 & 0,41 & 1,32 & 3,32 \\
\hline Tabebuia roseoalba & 8 & 0,67 & 1,54 & 1,10 & 3,31 \\
\hline Sebastiania brasiliensis & 15 & 1,26 & 0,47 & 1,54 & 3,27 \\
\hline Eugenia excelsa & 12 & 1,01 & 0,53 & 1,54 & 3,08 \\
\hline Peltogyne discolor & 14 & 1,17 & 1,02 & 0,88 & 3,08 \\
\hline Rinorea laevigata & 17 & 1,42 & 0,48 & 1,10 & 3,01 \\
\hline Simira sampaioana & 6 & 0,50 & 1,30 & 0,88 & 2,68 \\
\hline Euphorbiaceae indet. & 9 & 0,75 & 1,06 & 0,66 & 2,47 \\
\hline Eugenia cf. rostrata & 13 & 1,09 & 0,44 & 0,88 & 2,41 \\
\hline Araliaceae indet. & 3 & 0,25 & 1,50 & 0,66 & 2,41 \\
\hline Aspidosperma ramiflorum & 11 & 0,92 & 0,30 & 1,10 & 2,32 \\
\hline Parapiptadenia pterosperma & 6 & 0,50 & 0,70 & 1,10 & 2,30 \\
\hline Gochnatia polymorpha & 4 & 0,34 & 1,30 & 0,66 & 2,29 \\
\hline Eugenia sp.1 & 6 & 0,50 & 0,56 & 1,10 & 2,17 \\
\hline Chamaecrista ensiformis & 9 & 0,75 & 0,92 & 0,44 & 2,11 \\
\hline Platymiscium floribundum & 6 & 0,50 & 0,32 & 1,10 & 1,92 \\
\hline Phyllanthus sp.2 & 7 & 0,59 & 0,45 & 0,88 & 1,92 \\
\hline Porcelia macrocarpa & 6 & 0,50 & 0,42 & 0,88 & 1,81 \\
\hline Guazuma crinita & 4 & 0,34 & 0,47 & 0,88 & 1,69 \\
\hline Zollernia glabra & 5 & 0,42 & 0,29 & 0,88 & 1,59 \\
\hline Eugenia repanda & 5 & 0,42 & 0,25 & 0,88 & 1,55 \\
\hline
\end{tabular}




\begin{tabular}{|c|c|c|c|c|c|}
\hline Espécie & $\mathbf{N}$ & DR & DoR & FR & VI \\
\hline Eugenia punicifolia & 6 & 0,50 & 0,13 & 0,88 & 1,51 \\
\hline Spondias cf. venulosa & 2 & 0,17 & 0,86 & 0,44 & 1,46 \\
\hline Rudgea ovalis & 6 & 0,50 & 0,16 & 0,66 & 1,33 \\
\hline Zanthoxylum tingoassuiba & 3 & 0,25 & 0,38 & 0,66 & 1,29 \\
\hline Chrysophyllum gonocarpum & 5 & 0,42 & 0,20 & 0,66 & 1,28 \\
\hline Andradea floribunda & 2 & 0,17 & 0,87 & 0,22 & 1,26 \\
\hline Gallesia integrifolia & 1 & 0,08 & 0,92 & 0,22 & 1,23 \\
\hline Guapira aff. areolata & 3 & 0,25 & 0,31 & 0,66 & 1,22 \\
\hline Eugenia oxyoentophylla & 4 & 0,34 & 0,21 & 0,66 & 1,21 \\
\hline Coussarea capitata & 6 & 0,50 & 0,26 & 0,44 & 1,20 \\
\hline Schoepfia brasiliensis & 4 & 0,34 & 0,18 & 0,66 & 1,18 \\
\hline Trichilia pseudostipularis & 3 & 0,25 & 0,26 & 0,66 & 1,17 \\
\hline Simaba floribunda & 1 & 0,08 & 0,86 & 0,22 & 1,16 \\
\hline Pouteria reticulata & 4 & 0,34 & 0,15 & 0,66 & 1,15 \\
\hline Achatocarpus praecox & 3 & 0,25 & 0,19 & 0,66 & 1,11 \\
\hline Urera baccifera & 3 & 0,25 & 0,19 & 0,66 & 1,11 \\
\hline Celtis iguanaea & 1 & 0,08 & 0,79 & 0,22 & 1,09 \\
\hline Ceiba erianthos & 3 & 0,25 & 0,14 & 0,66 & 1,06 \\
\hline Talisia oliviformis & 3 & 0,25 & 0,33 & 0,44 & 1,03 \\
\hline Capparis brasiliana & 3 & 0,25 & 0,06 & 0,66 & 0,97 \\
\hline Aspidosperma gomezianum & 3 & 0,25 & 0,19 & 0,44 & 0,88 \\
\hline Eugenia schottiana & 3 & 0,25 & 0,17 & 0,44 & 0,86 \\
\hline Myrtaceae indet.2 & 2 & 0,17 & 0,21 & 0,44 & 0,82 \\
\hline Phyllostylon brasiliense & 2 & 0,17 & 0,43 & 0,22 & 0,81 \\
\hline Ziziphus glaziovii & 1 & 0,08 & 0,49 & 0,22 & 0,79 \\
\hline Pouteria psammophila & 2 & 0,17 & 0,15 & 0,44 & 0,76 \\
\hline Heteropterys schenckiana & 3 & 0,25 & 0,23 & 0,22 & 0,70 \\
\hline Coccoloba confusa & 2 & 0,17 & 0,08 & 0,44 & 0,69 \\
\hline Eugenia olivacea & 3 & 0,25 & 0,16 & 0,22 & 0,63 \\
\hline Celtis chichape & 1 & 0,08 & 0,32 & 0,22 & 0,63 \\
\hline Eugenia copacabanensis & 2 & 0,17 & 0,21 & 0,22 & 0,60 \\
\hline Eugenia stictosepala & 3 & 0,25 & 0,08 & 0,22 & 0,55 \\
\hline Dyssochroma viridiflora & 1 & 0,08 & 0,24 & 0,22 & 0,54 \\
\hline Myrtaceae indet.1 & 1 & 0,08 & 0,20 & 0,22 & 0,51 \\
\hline Ficus hirsuta & 1 & 0,08 & 0,19 & 0,22 & 0,49 \\
\hline Trichilia sp. & 1 & 0,08 & 0,17 & 0,22 & 0,47 \\
\hline Eugenia microcarpa & 1 & 0,08 & 0,14 & 0,22 & 0,44 \\
\hline Eugenia brasiliensis & 1 & 0,08 & 0,12 & 0,22 & 0,43 \\
\hline Chrysophyllum januariense & 1 & 0,08 & 0,12 & 0,22 & 0,42 \\
\hline Erythroxylum pulchrum & 1 & 0,08 & 0,10 & 0,22 & 0,40 \\
\hline Garcinia brasiliensis & 1 & 0,08 & 0,04 & 0,22 & 0,35 \\
\hline Eugenia aff. xanthoxyloides & 1 & 0,08 & 0,04 & 0,22 & 0,35 \\
\hline Randia armata & 1 & 0,08 & 0,04 & 0,22 & 0,35 \\
\hline Dalbergia frutescens & 1 & 0,08 & 0,04 & 0,22 & 0,35 \\
\hline Agonandra excelsa & 1 & 0,08 & 0,04 & 0,22 & 0,34 \\
\hline Quararibea turbinata & 1 & 0,08 & 0,03 & 0,22 & 0,34 \\
\hline Rutaceae indet. & 1 & 0,08 & 0,03 & 0,22 & 0,33 \\
\hline Myrciaria cf. floribunda & 1 & 0,08 & 0,03 & 0,22 & 0,33 \\
\hline Allophylus puberulus & 1 & 0,08 & 0,03 & 0,22 & 0,33 \\
\hline Eugenia neosilvestris & 1 & 0,08 & 0,03 & 0,22 & 0,33 \\
\hline Clusia fluminensis & 1 & 0,08 & 0,02 & 0,22 & 0,33 \\
\hline
\end{tabular}


O índice de diversidade de Shannon $\left(\mathrm{H}^{\prime}\right)$ foi de 3,60 nat.ind. ${ }^{-1}$ e a equabilidade (J') de 0,79 , valores relativamente reduzidos e, em parte, relacionados à concentração de indivíduos em poucas espécies. Embora inferior ao de trechos de encosta da Floresta Atlântica (ver Kurtz \& Araujo 2000), o índice de Shannon encontrado está dentro da faixa para florestas fluminenses localizadas em baixa altitude e submetidas à menor precipitação (ver Tab. 3).

Apesar de $S$. nervosa e P. longifolium terem somado $31 \%$ dos indivíduos amostrados, o que poderia sugerir tendência a uma estrutura de co-dominância, estas espécies apresentaram distribuições bastante definidas ao longo das encostas. Apenas na encosta voltada para leste (área C), as duas ocorreram juntas e com densidades elevadas; nas demais, foram exclusivas ou quase: $S$. nervosa nas encostas voltadas para noroeste (áreas A e D) e $P$. longifolium nas encostas voltadas para sul (áreas B e E).

A densidade variou muito entre as encostas (1480 a 3310 ind.ha ${ }^{-1}$; áreas B e C, respectivamente), enquanto a área basal apresentou pequena variação (21,6 a 25,4 $\mathrm{m}^{2}$.ha ${ }^{-1}$; áreas D e B). Para toda a amostragem, os valores foram de 2386 ind.ha $^{-1}$ e 23,6 $\mathrm{m}^{2}$.ha ${ }^{-1}$, respectivamente. As distribuições das classes de altura e diâmetro dos indivíduos amostrados (intervalos abertos na extremidade superior) são apresentadas nas figuras 4 e 5 . Com relação às alturas, são observadas algumas variações entre as áreas, principalmente entre as áreas B e C. Para a amostragem total, houve grande concentração de indivíduos nas classes entre 4 e 8 m (67,9\% do total; Fig. 4). As alturas variaram de 2 a $20 \mathrm{~m}$, com média de 6,8 $\pm 2,9 \mathrm{~m}$. As distribuições de diâmetros apresentaram a forma de $\mathrm{J}$ reverso, com maior ou menor concentração de indivíduos na primeira classe, indicando regeneração do componente arbustivo-arbóreo. Para a amostragem total, esta classe englobou quase metade $(49,5 \%)$ dos indivíduos amostrados (Fig. 5). Os diâmetros variaram de 5 a 39,0 cm (este último múltiplo), com média de 9,8 \pm $5,5 \mathrm{~cm}$.
Os percentuais de indivíduos bifurcados ou ramificados abaixo de 1,3 $\mathrm{m}$ variaram de 2,0 a 12,4 (áreas B e C, respectivamente); para toda a amostragem, o valor foi de 7,3\% Acredita-se que o maior percentual para a área C seja função da própria dinâmica da floresta numa encosta exposta aos constantes ventos do quadrante Nordeste, predominantes na região (ver Araujo 2000).

Os resultados acima indicaram que mesmo próximo às grotas ou em locais abrigados, aparentemente em bom estado de conservação, desenvolve-se uma floresta com alta densidade de indivíduos (embora variável) e porte reduzido. Estas características estão muito provavelmente relacionadas à baixa pluviosidade da região, à acentuada declividade das encostas, que condiciona a ocorrência de solos rasos, e à presença freqüente de afloramentos. De fato, variações na densidade e área basal de trechos da Floresta Atlântica estão freqüentemente relacionadas à sua localização em talvegues ou grotas, profundidade dos solos, ocorrência de afloramentos, orientação e declividade de encostas, exposição a ventos, pluviosidade e/ ou estado de conservação (e.g., Oliveira et al. 1995; Kurtz \& Araujo 2000; Moreno et al. 2003; Peixoto et al. 2005).

O dendrograma da análise de agrupamento (Fig. 6) indica a formação de dois grupos: o primeiro incluindo as parcelas das encostas voltadas para sul (áreas B e E) e para leste (área C, menos C5) e o segundo, as parcelas das encostas voltadas para noroeste (áreas A e D, mais a C5). No primeiro grupo, as parcelas de cada área formaram subgrupos, o que não aconteceu no segundo. O coeficiente de correlação cofenética foi de 0,79 .

Diferentes orientações de encostas condicionam diferentes características ambientais no que se refere à insolação, exposição a ventos, umidade, etc. No hemisfério Sul, encostas voltadas para o norte são mais quentes e secas, como resultado da maior insolação, enquanto encostas voltadas para o sul são mais frescas e úmidas (Oliveira et al. 1995). Na área de estudo, as encostas voltadas 

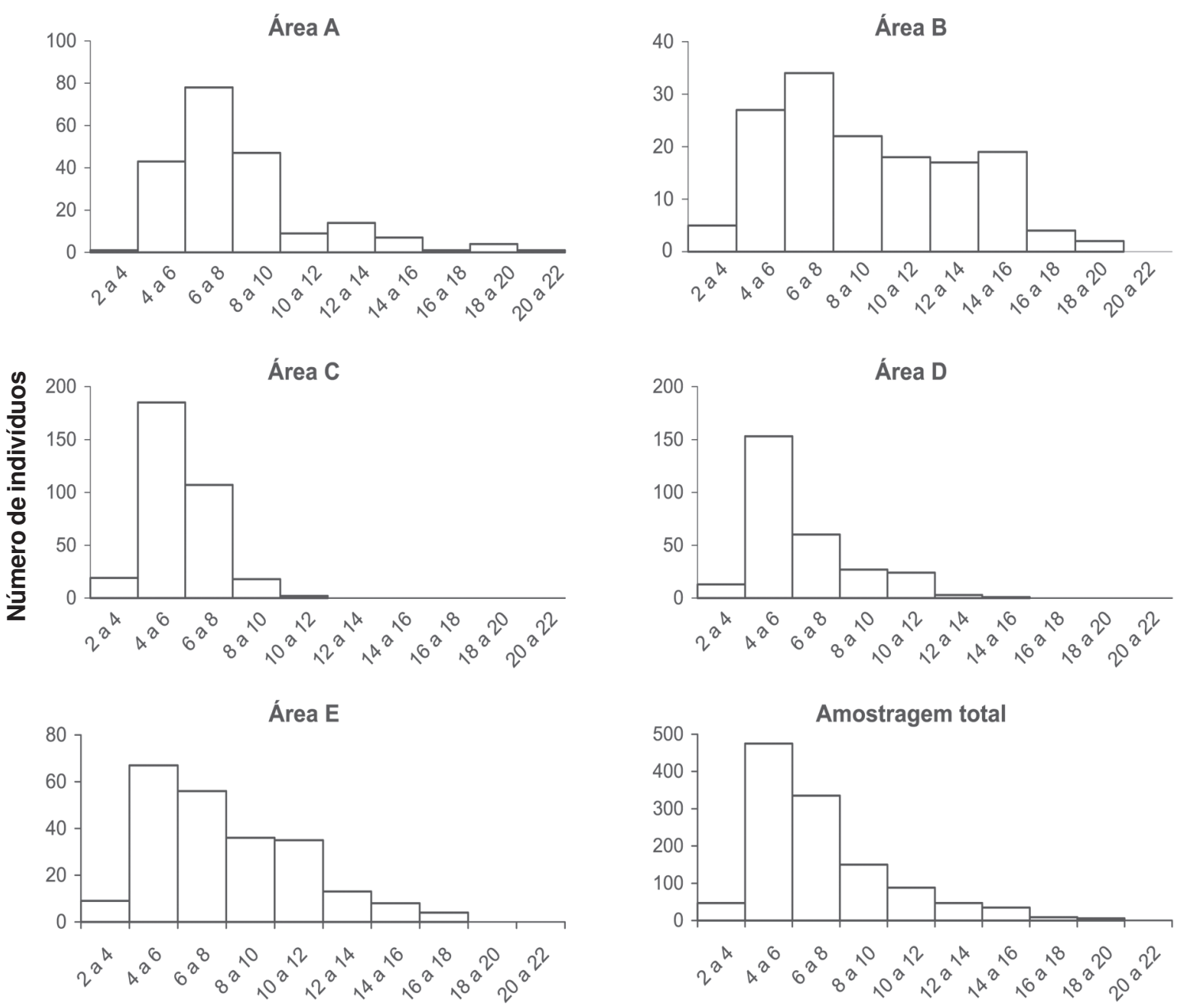

\section{Classes de altura (m)}

Figura 4 - Distribuições das classes de altura de indivíduos arbustivo-arbóreos de florestas da região de Emerenças, Área de Proteção Ambiental do Pau Brasil, Armação dos Búzios, RJ.

para leste ainda recebem os constantes ventos do quadrante Nordeste. Desta forma, as características ecológicas de cada encosta, como resultado de sua orientação, parecem estar promovendo diferenças na distribuição espacial das espécies, condicionando composições e estruturas próprias e a conseqüente formação dos grupos. Tais diferenças também foram detectadas por Sá (2006), que encontrou maior riqueza de espécies nas encostas voltadas para o quadrante Sul, principalmente nas áreas de Armação dos Búzios, Cabo Frio e ilha de Cabo Frio.
As florestas de Emerenças apresentaram, via de regra, similaridade florística muito baixa com outras florestas fluminenses (Tab. 3), mesmo tendo sido selecionados para comparação trabalhos desenvolvidos em áreas de baixa altitude $(<400 \mathrm{~m})$ e geograficamente próximas (distância $<181 \mathrm{~km}$ ). Só houve similaridade $(\mathrm{J}=0,26)$ com a floresta estudada por Farág (1999), situada sobre baixada muito próxima (distância $<3 \mathrm{~km}$ ) à área de estudo. Embora baixa $(\mathrm{J}=0,20)$, houve maior similaridade com a floresta de restinga da Reserva Ecológica Estadual de Jacarepiá, 
Tabela 3 - Coeficientes de similaridade de Jaccard (J) entre as florestas estudadas na região de Emerenças, Área de Proteção Ambiental do Pau Brasil, Armação dos Búzios, RJ, e outras florestas fluminenses. Alt.: altitude aproximada (metros acima do nível do mar); Pluv.: pluviosidade (média anual em mm); Dist.: distância aproximada em relação à área estudada (km); CI: critério de inclusão (DAP $\geq$ ); A/P: área amostrada (ha)/ número de pontos; N: número de indivíduos amostrados; S: número de espécies; I: espécies identificadas usadas para o cálculo de J; H’: índice de diversidade de Shannon (nat.ind. ${ }^{-1}$ ); e J': equabilidade.

\begin{tabular}{|c|c|c|c|c|c|c|c|c|c|c|c|c|}
\hline Local & Alt. & Pluv. & Dist. & CI & $\mathbf{A} / \mathbf{P}$ & $\mathbf{N}$ & $\mathbf{S}$ & I & $\mathbf{J}$ & $\mathbf{H}$ & $\mathrm{J} '$ & Fonte \\
\hline APA do Pau Brasil & $10-160$ & 822 & - & 5 & 0,5 & 1193 & 98 & 81 & - & 3,60 & 0,79 & Este estudo \\
\hline APA do Pau Brasil & $10-30$ & 822 & $<3$ & 5 & 0,5 & 1164 & 107 & 83 & 0,26 & 3,88 & 0,81 & Farág (1999) \\
\hline REE de Jacarepiá & $<10$ & 934 & 53 & 5 & 200 & 800 & 108 & 84 & 0,20 & 4,06 & 0,87 & Sá \& Araujo (2009) \\
\hline $\begin{array}{l}\text { São Francisco do } \\
\text { Itabapoana }\end{array}$ & $20-40$ & 1023 & 181 & 10 & 1 & 564 & 83 & 56 & 0,11 & 3,21 & 0,77 & $\begin{array}{l}\text { Silva \& Nascimento } \\
\text { (2001) }\end{array}$ \\
\hline EEE do Paraíso & 200 & 2558 & 106 & 5 & 150 & 592 & 138 & 115 & 0,06 & 4,20 & 0,85 & Kurtz \& Araujo (2000) \\
\hline $\begin{array}{l}\text { APA da Serra da } \\
\text { Capoeira Grande }\end{array}$ & $60-140$ & 1027 & 176 & 4,8 & 200 & 800 & 44 & 43 & 0,05 & 2,42 & 0,64 & Peixoto et al. (2005) \\
\hline Rio Bonito & $<150$ & $1500-2000$ & 64 & 5 & 0,4 & 698 & 106 & 94 & 0,05 & 3,91 & 0,84 & Carvalho et al. (2007) \\
\hline $\begin{array}{l}\text { APA da Bacia do Rio São } \\
\text { João/Mico Leão Dourado }\end{array}$ & $30-400$ & $1500-2000$ & 58 & 5 & 1 & 1591 & 161 & 141 & 0,03 & - & - & Carvalho et al. (2006) \\
\hline
\end{tabular}



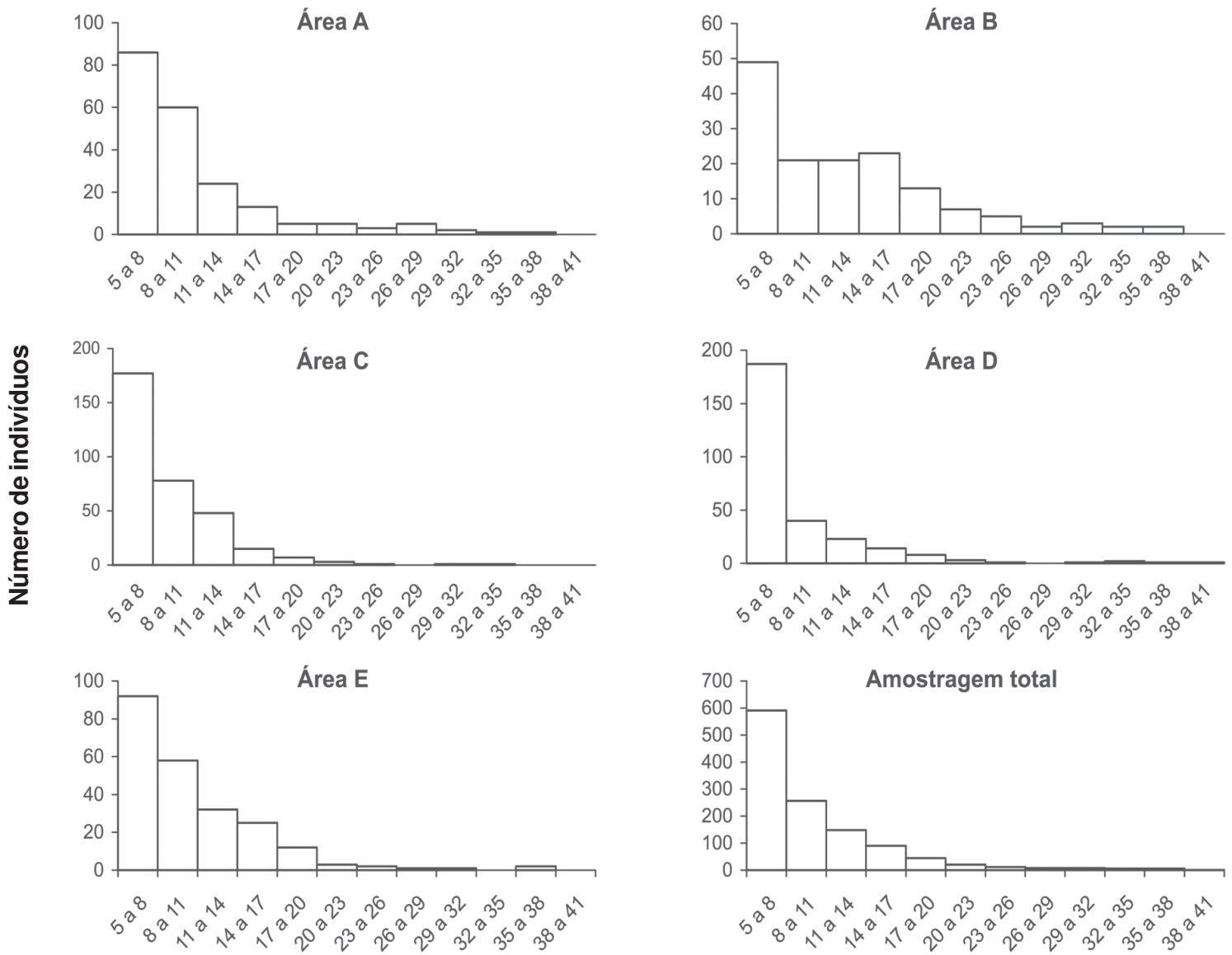

Classes de diâmetro $(\mathrm{cm})$

Figura 5 - Distribuições das classes de diâmetro de indivíduos arbustivo-arbóreos de florestas da região de Emerenças, Área de Proteção Ambiental do Pau Brasil, Armação dos Búzios, RJ.

Saquarema, do que em relação às áreas situadas sobre tabuleiro, morrotes ou nas primeiras elevações da Serra do Mar $(\mathrm{J}=0,11$ a 0,03). Florestas submetidas à maior pluviosidade apresentaram baixíssima similaridade com as florestas ora estudadas.

Análises de agrupamento de florestas do estado do Rio de Janeiro (Peixoto et al. 2004; Carvalho et al. 2006) tendem a agrupar as poucas áreas até então estudadas situadas em baixa altitude, próximas ao mar e submetidas à baixa pluviosidade. Apesar disto, os resultados aqui obtidos sugerem que a similaridade entre estas florestas pode ser muito baixa, em função da heterogeneidade florística condicionada por distintos micro-habitats (relacionados à orientação de encostas, faixa altitudinal, condições edáficas e climáticas etc). Este fato confere importância ecológica e evolutiva ímpar às florestas situadas no Centro de Diversidade Vegetal de Cabo Frio, cujos últimos remanescentes, sobretudo os da área em estudo, necessitam urgentemente da tutela da união. Isto deve ser feito através da criação de Unidade de Conservação de Proteção Integral (de acordo com o Sistema Nacional de Unidades de Conservação - SNUC), uma vez que Áreas de Proteção Ambiental são unidades muito frágeis para a efetiva preservação da biodiversidade. 


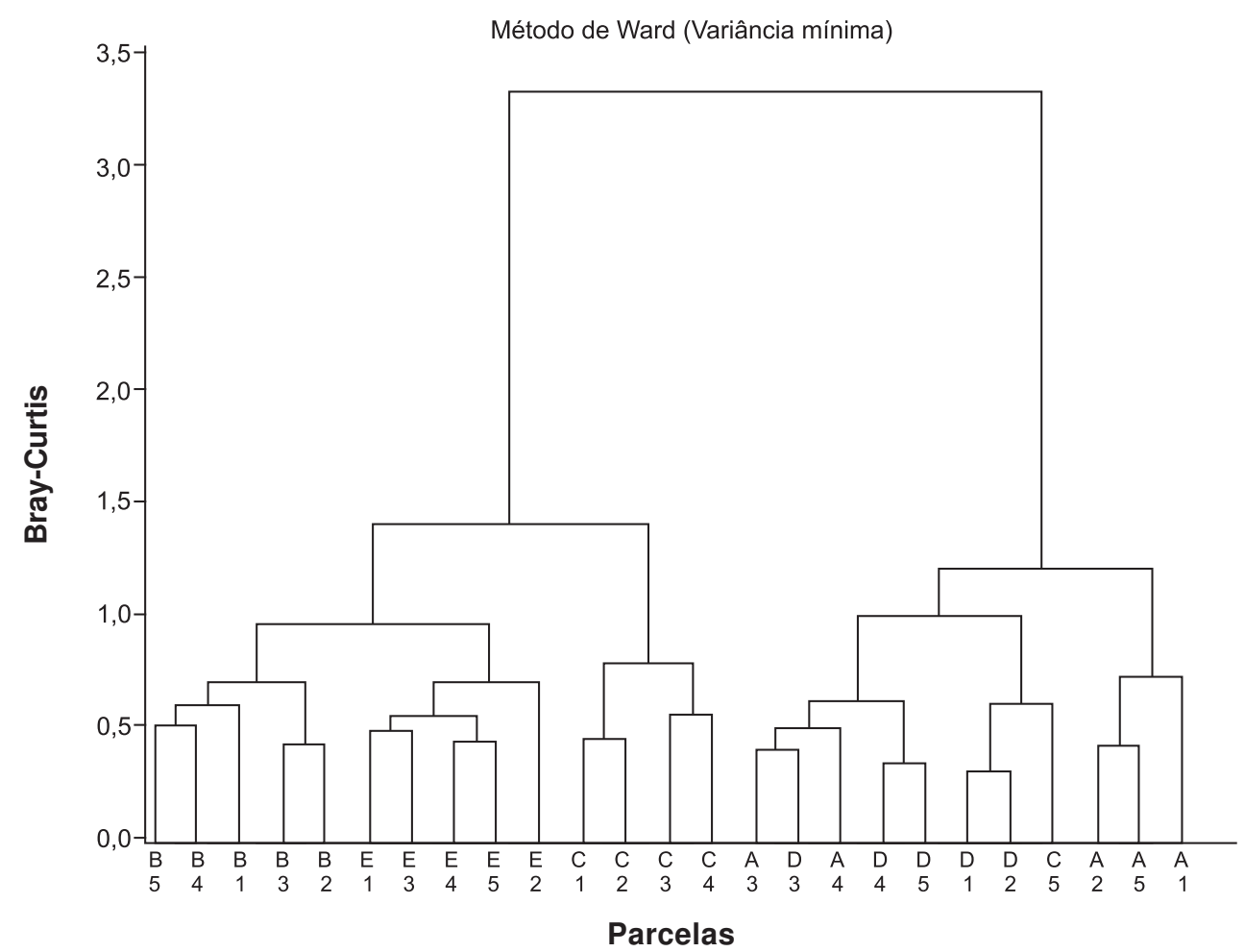

Figura 6 - Dendrograma da análise de agrupamento do componente arbustivo-arbóreo em cinco blocos (A-E) de parcelas (1-5) em florestas da região de Emerenças, Área de Proteção Ambiental do Pau Brasil, Armação dos Búzios, RJ.

\section{Agradecimentos}

Os autores gostariam de agradecer ao Instituto de Pesquisas Jardim Botânico do Rio de Janeiro, pelo apoio financeiro; à Secretaria de Meio Ambiente da Prefeitura Municipal de Armação dos Búzios, na pessoa do exsecretário Carlos Alberto Muniz (1998-2000), pelo apoio incondicional que permitiu o desenvolvimento deste e de outros estudos na região; aos hotéis e pousadas locais (João Fernandes, Búzios Bauen Club, La Mandragora e Lestada), que gentilmente alojaram as equipes de trabalho; ao técnico de campo Jorge Caruso Gomes, ao auxiliar local José Martinho Rodrigues Leal, aos ex-alunos Adriana Q. Lobão, Danielle S. Fernandes e Rodrigo Coelho de Sá e aos buzianos Lívia Xavier Alcântara, Alessandro Terra Paz e Babington de Souza, pela inestimável ajuda nos trabalhos de campo; aos taxonomistas Adriana Q. Lobão (Annonaceae), André M. A. Amorim (Malpighiaceae), Arline S. de Oliveira (Euphorbiaceae), Carine G. P. Quinet
(Apocynaceae), Genise V. Somner (Sapindaceae), Haroldo C. Lima (Fabaceae), Jorge Pedro P. Carauta (Cannabaceae), Lucia d'A.F. Carvalho (Solanaceae), Marcelo C. Souza (Myrtaceae), Maria Bernadete Costa e Silva (Brassicaceae), Mario Gomes (Rubiaceae), Massimo G. Bovini (Malvaceae), Nilda Marquete F. Silva (Violaceae), Ricardo C. C. Reis (Arecaceae), Roberto L. Esteves (Asteraceae) e Sebastião J. Silva Neto (Rubiaceae), pela colaboração na identificação do material botânico.

\section{REFERÊNCIAS BIBLIOGRÁFICAS}

Ab'Saber, A. N. 1974. O domínio morfoclimático semi-árido das caatingas brasileiras. Geomorfologia 43: 1-39. 1977. Espaços ocupados pela expansão dos climas secos na América do Sul por ocasião dos períodos glaciais quaternários. Paleoclimas 3: 1-19.

APG II. 2003. An update of the Angiosperm Phylogeny Group classification for the orders and families of flowering plants: 
APG II. Botanical Journal of the Linnaean Society 141: 399-436.

Araujo, D. S. D. 1997. Cabo Frio Region: Southeastern Brazil. In: Davis, S.D.; Heywood, V.H.; Herrera-MacBryde, O.; Villa-Lobos, J. \& Hamilton, A.C. (eds.). Centres of plant diversity: a guide and strategy for their conservation. Volume 3: The Americas. IUCN Publications Unit, Cambridge. Pp. 373-375. 2000. Análise florística e fitogeográfica das restingas do estado do Rio de Janeiro. Tese de Doutorado. Universidade Federal do Rio de Janeiro, Rio de Janeiro, 176p.

; Lima, H. C.; Farág, P. R. C.; Lobão, A. Q.; Sá, C. F. C. \& Kurtz, B. C. 1998. O Centro de Diversidade Vegetal de Cabo Frio: levantamento preliminar da flora. In: Anais do IV Simpósio de Ecossistemas Brasileiros, Águas de Lindóia, vol. 3. Pp. 147-157.

Carvalho, F. A.; Nascimento, M. T. \& Braga, J. M. A. 2006. Composição e riqueza florística do componente arbóreo da Floresta Atlântica submontana na região de Imbaú, município de Silva Jardim, RJ. Acta Botanica Brasilica 20(3): 727-740.

.2007. Estrutura e composição florística do estrato arbóreo de um remanescente de Mata Atlântica submontana no município de Rio Bonito, RJ, Brasil (Mata Rio Vermelho). Revista Árvore 31(4): 717-730.

Dantas, H. G. R.; Lima, H. C. \& Boher, C. B. A. 2009. Mapeamento da vegetação e da paisagem do município de Armação dos Búzios, Rio de Janeiro. Rodriguésia 60(1): 25-38.

Davis, S. D.; Heywood, V. H.; HerreraMacBryde, O.; Villa-Lobos, J. \& Hamilton, A. C. 1997. Centres of plant diversity: a guide and strategy for their conservation. Vol. 3: The Americas. IUCN Publications Unit, Cambridge.

Farág, P. R. C. 1999. Estrutura do estrato arbóreo de mata litorânea semicaducifólia sobre solo arenoso no município de Búzios,
RJ. Dissertação de Mestrado. Museu Nacional/Universidade Federal do Rio de Janeiro, Rio de Janeiro, 87p.

Fernandes, D. S. 2005. Estrutura de uma floresta seca de restinga em Cabo Frio, RJ. Dissertação de Mestrado. Escola Nacional de Botânica Tropical/Instituto de Pesquisas Jardim Botânico do Rio de Janeiro, Rio de Janeiro, 38p.

Gentry, A. H. 1995. Diversity and floristic composition of neotropical dry forests. In: Bullock, S.H.; Mooney, H.A. \& Medina, E. (eds.). Seasonally dry tropical forests. Cambridge University Press. Pp. 146-194.

Kurtz, B. C. \& Araujo, D. S. D. 2000. Composição florística e estrutura do componente arbóreo de um trecho de Mata Atlântica na Estação Ecológica Estadual do Paraíso, Cachoeiras de Macacu, Rio de Janeiro, Brasil. Rodriguésia 51(78/79): 69-111.

Martins, F. R. 1993. Estrutura de uma floresta mesófila. 2ed. Editora da UNICAMP, Campinas, 246p.

Moreno, M. R.; Nascimento, M. T. \& Kurtz, B. C. 2003. Estrutura e composição florística do estrato arbóreo em duas zonas altitudinais na Mata Atlântica de encosta da região do Imbé, RJ. Acta Botanica Brasilica 17(3): 371-386.

Mueller-Dombois, D. \& Ellenberg, H. 1974. Aims and methods of vegetation ecology. John Wiley \& Sons, New York, 547p.

Oliveira, R. R.; Zaú, A. S.; Lima, D. F.; Silva, M. B. R.; Vianna, M. C.; Sodré, D. O. \& Sampaio, P.D. 1995. Significado ecológico da orientação de encostas no maciço da Tijuca, Rio de Janeiro. In: Esteves, F. A. (ed.). Estrutura, funcionamento e manejo de ecossistemas brasileiros. Série Oecologia Brasiliensis, vol. 1. PPGE-UFRJ, Rio de Janeiro. Pp. 523-541.

Oliveira-Filho, A. T. \& Fontes, M. A. L. 2000. Patterns of floristic differentiation among Atlantic forests in southeastern Brazil and the influence of climate. Biotropica 32(4b): 793-810. 
Peixoto, G. L.; Martins, S. V.; Silva, A. F. \& Silva, E. 2004. Composição florística do componente arbóreo de um trecho de Floresta Atlântica na Área de Proteção Ambiental da Serra da Capoeira Grande, Rio de Janeiro, RJ, Brasil. Acta Botanica Brasilica 18(1): 151-160.

2005. Estrutura do componente arbóreo de um trecho de Floresta Atlântica na Área de Proteção Ambiental da Serra da Capoeira Grande, Rio de Janeiro, RJ, Brasil. Acta Botanica Brasilica 19(3): 539-547.

Richards, P. W. 1981. The tropical rain forest: an ecological study. 2ed. Cambridge University Press, Cambridge, 450p.

Sá, C. F. C. 2006. Estrutura, diversidade e conservação de angiospermas no Centro de Diversidade de Cabo Frio, Rio de Janeiro. Tese de Doutorado. Universidade Federal do Rio de Janeiro, Rio de Janeiro, 251p.

\& Araujo, D. S. D. 2009. Estrutura e florística de uma floresta de restinga em Ipitingas, Saquarema Rio de Janeiro, Brasil. Rodriguésia 60(1): 147-170.

Scarano, F. R. 2002. Structure, function and floristic relationships of plant communities in stressful habitats marginal to the Brazilian Atlantic rainforest. Annals of Botany 90: 517-524.

Shepherd, G. J. 2006. FitopacShell 1.6.4. Manual, versão preliminar. Departamento de Botânica, UNICAMP, Campinas, 78p.

Silva, G. C. \& Nascimento, M. T. 2001. Fitossociologia de um remanescente de mata sobre tabuleiros no norte do estado do Rio de Janeiro (Mata do Carvão). Revista Brasileira de Botânica 24(1): 51-62.

Souza, V. C \& Lorenzi, H. 2005. Botânica sistemática: guia ilustrado para identificação das famílias de angiospermas da flora brasileira, baseado em APG II. Instituto Plantarum, Nova Odessa, 640p.

The International Plant Names Index (http:// www.ipni.org). Acesso em 24-25/5/2008.

Tropicos.org. Missouri Botanical Garden. (http://www.tropicos.org). Acesso em 2425/5/2008.

Ule, E. 1901 (1967). A vegetação de Cabo Frio. Boletim Geográfico 26(200): 21-32.

Ururahy, J. C. C.; Collares, J. E. R. \& Santos, M. M. 1987. Nota sobre a formação fisionômico-ecológica disjunta da estepe nordestina na área do pontal de Cabo Frio, RJ. Revista Brasileira de Geografia 49(4): 25-29.

; Collares, J. E. R.; Santos, M. M. \& Barreto, R. A. A. 1983. Vegetação: as regiões fitoecológicas, sua natureza e seus recursos econômicos; estudo fitogeográfico. In: Folhas SF.23/24 Rio de Janeiro/Vitória; geologia, geomorfologia, pedologia, vegetação e uso potencial da terra. Projeto RADAMBRASIL, Rio de Janeiro, vol. 32. Pp. 553-623.

Valentin, J. L. 2000. Ecologia numérica: uma introdução à análise multivariada de dados ecológicos. Interciência, Rio de Janeiro, 117p.

Zar, J. H. 1996. Biostatistical analysis. 3ed. Prentice Hall, New Jersey, 870p. 